\title{
The effect of positive expiratory pressure (PEP) therapy on symptoms, quality of life and incidence of re-exacerbation in patients with acute exacerbations of chronic obstructive pulmonary disease: a multicentre, randomised controlled trial
}

\author{
Christian R Osadnik, ${ }^{1,2}$ Christine F McDonald, ${ }^{2,3}$ Belinda R Miller, ${ }^{4}$ Catherine J Hill, ${ }^{2,5}$ \\ Ben Tarrant, ${ }^{6}$ Ranjana Steward, ${ }^{6}$ Caroline Chao, ${ }^{5}$ Nicole Stodden, ${ }^{5}$ \\ Cristino C Oliveira, ${ }^{1}$ Nadia Gagliardi, ${ }^{3}$ Anne E Holland ${ }^{1,2,6}$
}

\begin{abstract}
${ }^{1}$ School of Physiotherapy, La Trobe University, Melbourne, Victoria, Australia

${ }^{2}$ Institute for Breathing and Sleep, Austin Health,

Melbourne, Victoria, Australia ${ }^{3}$ Department of Respiratory and Sleep Medicine, Austin Health, Melbourne, Victoria, Australia

${ }^{4}$ Department of Allergy, Immunology and Respiratory Medicine, Alfred Health, Melbourne, Victoria, Australia ${ }^{5}$ Department of Physiotherapy, Austin Health, Melbourne, Victoria, Australia ${ }^{6}$ Department of Physiotherapy, Alfred Health, Melbourne, Victoria, Australia
\end{abstract}

\section{Correspondence to}

Christian Robert Osadnik, La Trobe University, Alfred Clinical School, Level 4, The Alfred Centre, Commercial Road, Prahran, Melbourne, VIC 3181, Australia; christian.osadnik@monash.edu

Received 13 February 2013 Revised 13 August 2013 Accepted 15 August 2013 Published Online First 4 September 2013

\footnotetext{
To cite: Osadnik $C R_{\text {, }}$ McDonald CF, Miller BR, et al. Thorax 2014:69: 137-143.
}

\begin{abstract}
Background Positive expiratory pressure (PEP) is a technique used to enhance sputum clearance during acute exacerbations of chronic obstructive pulmonary disease (AECOPD). The impact of PEP therapy during acute exacerbations on clinically important outcomes is not clear. This study sought to determine the effect of PEP therapy on symptoms, quality of life and future exacerbations in patients with AECOPD.
\end{abstract}

Methods 90 inpatients (58 men; mean age 68.6 years, $\mathrm{FEV}_{1} 40.8 \%$ predicted) with AECOPD and sputum expectoration were randomised to receive usual care (including physical exercise) \pm PEP therapy. The Breathlessness, Cough and Sputum Scale (BCSS), St George's Respiratory Questionnaire (SGRQ) and BODE index (Body mass index, airflow Obstruction, Dyspnoea, Exercise tolerance) were measured at discharge, 8 weeks and 6 months following discharge, and analysed via linear mixed models. Exacerbations and hospitalisations were recorded using home diaries.

Results There were no significant between-group differences over time for BCSS score [mean (SE) at discharge $5.2(0.4)$ vs $5.0(0.4)$ for PEP and control group, respectively; $p=0.978$ ] or SGRQ total score [41.6 (2.6) vs 40.8 (2.8) at 8 weeks, $p=0.872$ ]. Dyspnoea improved more rapidly in the PEP group over the first 8 weeks $(p=0.006)$, however these benefits were not observed at 6 months. Exacerbations $(p=0.986)$ and hospitalisations ( $p=0.359)$ did not differ between groups.

Conclusions We found no evidence that PEP therapy during AECOPD improves important short-term or longterm outcomes. There does not appear to be a routine role for PEP therapy in the management of such individuals.

\section{INTRODUCTION}

Acute exacerbations of chronic obstructive pulmonary disease (AECOPD) are clinically important events known to accelerate lung function decline, ${ }^{12}$ decrease quality of life (QOL) ${ }^{3}$ and increase the risk of mortality. ${ }^{4}$ They are a common cause of hospital admission and are associated with recurrent exacerbations, ${ }^{5}$ thereby contributing significantly to the

\section{Key messages}

What is the key question?

- Does performance of airway clearance therapy via positive expiratory pressure (PEP) during an acute exacerbation of chronic obstructive pulmonary disease (AECOPD) improve symptoms, quality of life and incidence of future exacerbations?

What is the bottom line?

- PEP therapy conferred no additional benefit to usual care on key clinical outcomes, suggesting this form of therapy is unlikely to be routinely indicated for individuals with an AECOPD.

\section{Why read on?}

- This large randomised and controlled multicentre study provides some of the first high-quality evidence regarding the efficacy of airway clearance therapy via PEP therapy and, in doing so, highlights an area of practice that may need careful consideration of its clinical efficacy.

total healthcare burden of chronic obstructive pulmonary disease (COPD).

Airway clearance techniques (ACT) involve the application of external forces and manipulation of lung volumes, pulmonary pressures and gas flow in order to shear sputum from the airway lumen towards the mouth. ${ }^{6}$ Physiotherapists frequently prescribe ACTs during AECOPDs and perceive their role to be important, ${ }^{7}$ however, their clinical impact appears small. ${ }^{8}$ Positive expiratory pressure (PEP) therapy involves exhaling against a mild resistance, with the aim of shifting the equal pressure point peripherally to maximise airflow behind sputum and protect against dynamic airway collapse. It appears to confer greater short-term benefit than other $\mathrm{ACTs}^{8}$ such as a reduced need for and duration of ventilatory assistance, ${ }^{9}{ }^{10}$ and have been recommended for patients with an AECOPD. ${ }^{11}$ The increased expiratory time 
associated with PEP may reduce dynamic hyperinflation and improve dyspnoea, therefore addressing a key therapeutic aim during an AECOPD. ${ }^{12}$ The long-term effects of performing PEP therapy during an AECOPD on clinically important outcomes such as the incidence of future AECOPDs and QOL have not been investigated. ${ }^{8}$

The primary aim of this study was to determine whether the addition of PEP therapy to usual medical care improved symptoms, QOL and incidence of future exacerbations in patients hospitalised with an AECOPD. The secondary aim was to identify whether any baseline characteristics were associated with improved symptoms at discharge.

\section{METHODS}

\section{Participants and study design}

This multicentre, randomised controlled trial (RCT) was conducted at two public tertiary hospitals in Melbourne, Australia, between August 2010 and January 2013. Ethics approval was obtained from Alfred Health (70/10), Austin Health (H2010/ 03883) and La Trobe University (10-022), and the study was registered at http://www.clinicaltrials.gov on 7 April 2010 (identifier: NCT01101282). All patients hospitalised due to an AECOPD were screened by study personnel, and those with evidence of sputum expectoration or a history of chronic sputum production ('regularly expectorated sputum on most days') who provided informed consent were recruited from respiratory units within $48 \mathrm{~h}$ of admission. They were ineligible for recruitment if they had a respiratory condition deemed more significant than COPD (eg, clinical history of primary bronchiectasis, asthma or lung cancer requiring active therapy) even if coexistent with COPD, if they had established airway clearance routines, were breathing via an artificial airway or PEP therapy was contraindicated (undrained pneumothorax; significant haemoptysis; recent facial, oral, oesophageal or skull surgery/trauma; surgical or nonsurgical lung volume reduction procedures, lung transplantation or pneumonectomy within the last 6 months).

Participants were randomly assigned by the treating physiotherapist using consecutively numbered, sealed opaque envelopes to receive a control (usual care) or PEP (usual care+PEP therapy) intervention during their inpatient admission. Block randomisation (blocks of 30), stratified by site, was performed using a webbased sequence generator (http://www.randomization.com) by personnel external to the study. Only participants and treating physiotherapists had knowledge of group allocation throughout the study. The allocated intervention continued throughout any readmissions during the 6-month follow-up period.

\section{Interventions}

Control group (usual care)

Usual care consisted of medical therapy including bronchodilators, corticosteroids, antibiotics, supplemental oxygen, prescribed in accordance with COPDX guidelines ${ }^{13}$; non-invasive ventilation (NIV) if indicated, prescribed according to hospital protocols; and allied health assessment and intervention, as required. Physiotherapists delivered a standardised physical exercise training regime that commenced as early as possible with the aim of achieving $30 \mathrm{~min} /$ day of walking or equivalent lower limb exercise. Participants did not perform any ACTs except coughing, as needed. In the event of a serious clinical deterioration requiring airway clearance, additional ACTs were provided by the ward physiotherapist, as determined by a senior respiratory registrar or consultant. This was ceased at the earliest onset of clinical improvement. Upon discharge from hospital, participants were encouraged to resume usual activities and remain as physically active as possible.

\section{PEP group (usual care+PEP)}

Participants performed PEP therapy via a mask (Astra Tech AB, Molndal, Sweden) in an upright position with elbows resting on a table. Participants were instructed to breathe at tidal volume with a slightly active expiration for $8-10$ breaths to achieve a pressure of $10-20 \mathrm{~cm} \mathrm{H}_{2} \mathrm{O}$, monitored initially via a manometer. This was followed by one huff from a low lung volume (small inspiration, prolonged expiration), one huff from a mid-lung volume (moderate inspiration, moderate expiration) and two strong coughs. ${ }^{14}$ Five repetitions were performed each session, as tolerated, totalling approximately $20 \mathrm{~min}$ duration. If the mask interface was unable to be used effectively, a mouthpiece attachment was connected instead. Each day participants were supervised once and encouraged to perform two further independent sessions using a laminated written instruction card. Daily therapy continued until hospital discharge or $24 \mathrm{~h}$ without sputum expectoration, whichever came first. No other ACTs were performed except coughing, as needed.

\section{Outcomes and data collection}

Participants were assessed at admission, discharge, 8 weeks and 6 months following discharge. The primary outcome was selfreported symptom severity as measured via the breathlessness, cough and sputum scale (BCSS). This validated ${ }^{15}$ instrument generates a total daily score ranging from 0 (no symptoms) to 12 (severely affected), with mean changes of 0.3 considered small, 0.6 moderate and $\geq 1$ substantial. Daily BCSS scores were recorded throughout the entire 6 -month study period without aggregation over time.

The principal secondary outcome was the St George's Respiratory Questionnaire (SGRQ) ${ }^{16}$ (1-month Australian version), measured at all assessments except discharge. Use of ventilatory assistance and hospital length of stay was calculated at discharge. During the initial admission, growth of bacterial or viral organisms in sputum samples was recorded, and sputum colour was rated by an assessor using the 5-point Bronkotest sputum colour chart (Bronkotest, London, UK). Measures of body mass index (BMI), lung function severity $\left(\mathrm{FEV}_{1} \%\right)$, dyspnoea (modified Medical Research Council (mMRC) scale) ${ }^{17}$ and exercise tolerance $(6 \text { min walk distance }(6 \mathrm{MWD}))^{18}$ were recorded at all assessments except admission to derive the BODE index. ${ }^{18}$

A paper-based home diary comprising the BCSS plus antibiotic and oral corticosteroid use was completed daily throughout the study period. Compliance was monitored via telephone calls that were fortnightly until 8 weeks then monthly until 6 months. The number of AECOPDs, respiratory-related hospital admissions (total number, time to first episode, and total hospital days) and all-cause mortality were recorded at 8 weeks and 6 months. An AECOPD was defined as a worsening of symptoms (increase in daily total BCSS score of $\geq 1$ ) or healthcare utilisation (HCU) with commencement of antibiotics and/or corticosteroids. ${ }^{19}$ Subsequent AECOPDs were distinguished by at least 5 days of stable symptom scores preceding an increase in symptoms or treatment, where data were available. Participation in pulmonary rehabilitation during the follow-up period was also recorded, as a potential confounder of long-term outcomes.

A sample size of 98 was calculated as sufficient to detect a 1-point between-group difference in total BCSS score with $80 \%$ power and 95\% confidence, based on a daily total score SD of 1.97 during an AECOPD, ${ }^{15}$ and a one-tailed hypothesis. An additional $20 \%$ allowance for loss to follow-up was planned. 


\section{Data analysis}

Linear mixed model (LMM) analyses were performed using raw score data from all outcomes with repeated-measures. Each model comprised three fixed effects: group (PEP or control), time (treated as categorical with levels of discharge, 8 weeks and 6 months from discharge), and a group $\times$ time interaction. All LMM analyses incorporated these three terms, irrespective of significance, and were performed using an autoregressive repeated covariance type. Estimates of group differences at each timepoint were made using data derived from the interaction term. Baseline data, where available, were incorporated into the model as a covariate. No missing data were manually imputed in accordance with the principles of the LMM method. ${ }^{20}$ The effect of treatment over time (interaction effect) constituted the principal endpoint of analyses, however, posthoc between-group comparisons at each relevant time point were performed using a least significant differences adjustment.

Group comparisons for outcomes measured only at discharge and 6 months were performed using unpaired t tests, MannWhitney U tests or $\chi^{2}$ tests for outcomes with data that were normally distributed, non-normally distributed or calculated in count form, respectively. Time to first event data (AECOPDs, hospitalisations) were assessed via Kaplan-Meier survival analysis using log-rank tests to compare groups.

Subgroup analyses were specified a priori to investigate the effect of the initial exacerbation nature (infective vs noninfective) and the requirement for ventilatory assistance on the primary outcome. For this purpose, an infective exacerbation was defined as a 'type 1' AECOPD $^{21}$ with evidence of purulent/ coloured sputum (Bronkotest colours 3-5) and either a raised C-reactive protein $(>11 \mathrm{mg} / \mathrm{L})$ or isolation of bacterial or viral pathogen in sputum culture. The effect of a subsequent exacerbation on the primary outcome after discharge was also explored. Each subgroup analysis was performed via addition of a subgroup category, and a subgroup category $\times$ group interaction as fixed effects into the LMM.

The secondary aim of the study was addressed by exploring the effect of baseline variables thought to influence symptom severity at discharge using stepwise linear regression with bidirectional elimination. Factors were included when $\mathrm{p}<0.05$ and excluded where $\mathrm{p}<0.10$. These variables were age, baseline $\mathrm{FEV}_{1}$, pack-year smoking history, exacerbation type, usual cough and sputum production, sputum colour, admission arterial blood gas and the need for ventilatory assistance in the first

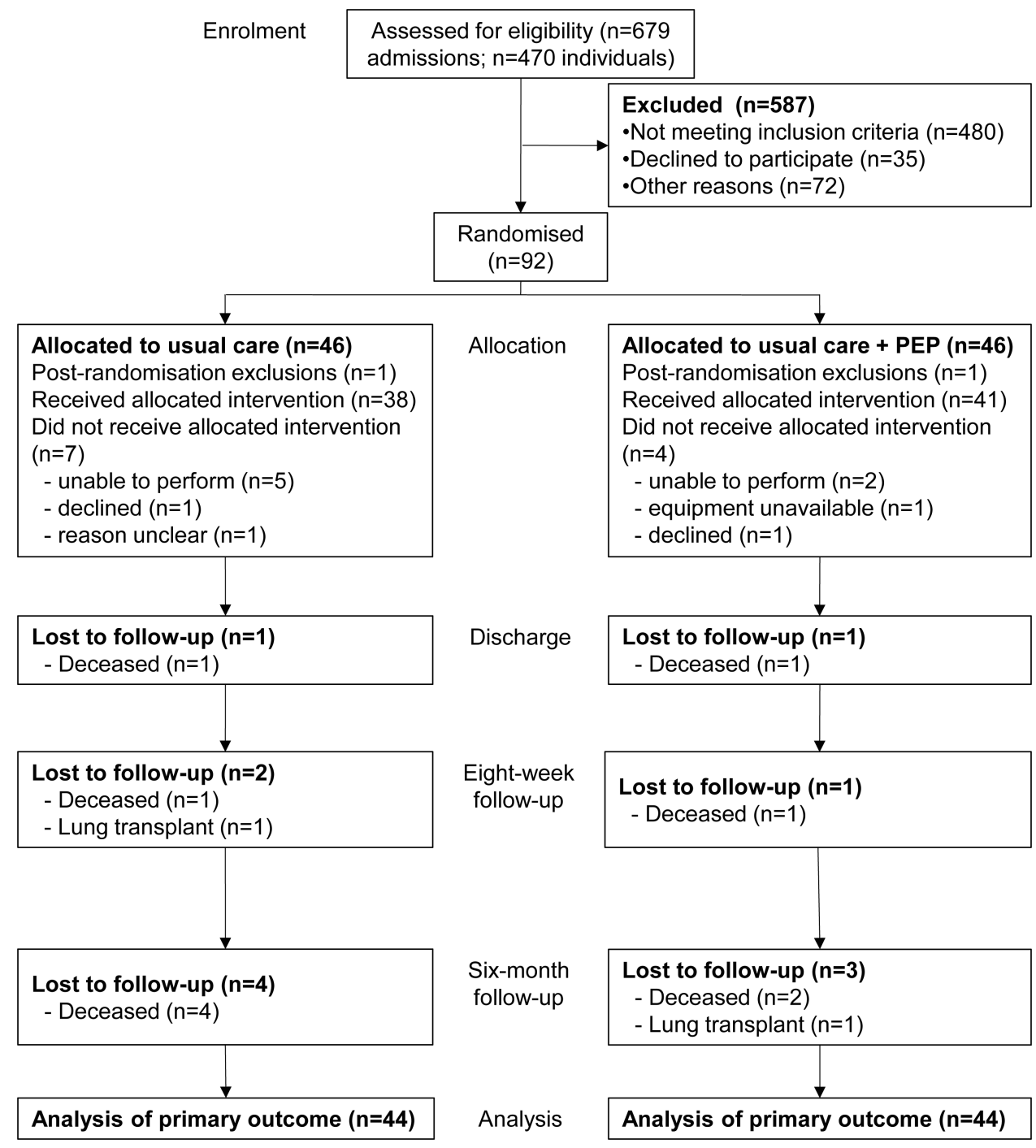

Figure 1 Flow of participants through the study (CONSORT diagram). PEP, positive expiratory pressure. 
$48 \mathrm{~h}$. All analyses were performed using SPSS V.20 (SPSS, Chicago, Illinois, USA). p Values less than 0.05 were considered statistically significant.

\section{RESULTS}

Ninety-two participants were recruited from 679 patient admissions (figure 1). The most common reasons for failing to meet the study criteria were a non-productive cough, or the admission was not due to an AECOPD. Two participants were excluded after randomisation without prior knowledge of their group allocation. One did not provide appropriate informed consent (PEP group) while the other withdrew consent due to concerns regarding the risks of PEP (control group). Table 1 shows the key participant characteristics of both groups.

\section{Protocol tolerance and safety}

During the initial hospital admission, 17 participants required a mouthpiece for PEP therapy due to concurrent oxygen or noninvasive ventilation, difficulty maintaining an airtight seal, discomfort or other reasons. Four participants were unable to perform any PEP throughout their admission, while six did not complete the required number of supervised sessions. This was due to fatigue/drowsiness, severe dyspnoea, onset of haemoptysis, acute delirium, lack of equipment or declining physiotherapy. One participant reported dizziness and palpitations after PEP (known resting tachycardia), and another experienced a transient episode of vocal cord dysfunction (known unstable comorbidity), however, both completed the full study protocol. Eight participants did not complete their independent PEP sessions (reasons not specified) and 12 (control group) were unable

Table 1 Participant characteristics

\begin{tabular}{|c|c|c|}
\hline Participant characteristics & Control $(n=45)$ & $\operatorname{PEP}(n=45)$ \\
\hline Age, years & $67.8(11.6)$ & $69.5(9.8)$ \\
\hline Gender, male:female & $30: 15$ & $28: 17$ \\
\hline Body mass index, $\mathrm{kg} / \mathrm{m}^{2}$ & $26.5(6.4)$ & $24.4(5.2)$ \\
\hline Smoking pack years & $56.0(41.3)$ & $72.3(45.9)$ \\
\hline $\mathrm{FEV}_{1}$, litres & $1.23(0.66)$ & $0.98(0.54)$ \\
\hline $\mathrm{FEV}_{1}, \%$ predicted & $44.4(20.2)$ & $37.3(19.7)$ \\
\hline Usual sputum producer, n (\%) & $26(58)$ & $28(62)$ \\
\hline Purulent or coloured sputum, n (\%)* & $31(86)$ & $34(94)$ \\
\hline Home oxygen, n (\%) & $7(16)$ & $12(27)$ \\
\hline Respiratory comorbidity, n (\%) & $18(40)$ & $18(40)$ \\
\hline Cardiac comorbidity, n (\%) & $20(44)$ & $23(51)$ \\
\hline AECOPD type $1, n(\%)$ & $22(49)$ & $26(58)$ \\
\hline AECOPD type $2, n(\%)$ & $11(24)$ & $14(31)$ \\
\hline AECOPD type $3, \mathrm{n}(\%)$ & $12(27)$ & $5(11)$ \\
\hline pH & $7.40(0.06)$ & $7.41(0.05)$ \\
\hline $\mathrm{P}_{\mathrm{a}} \mathrm{CO}_{2}, \mathrm{~mm} \mathrm{Hg}$ & $48.0(14.3)$ & $47.5(12.5)$ \\
\hline $\mathrm{P}_{\mathrm{a}} \mathrm{O}_{2}, \mathrm{~mm} \mathrm{Hg}$ & $69.9(29.8)$ & $72.2(29.7)$ \\
\hline Baseline BCSS & $7.5(2.2)$ & $7.5(2.0)$ \\
\hline Baseline SGRQ total & $49.0(19.5)$ & $49.9(18.3)$ \\
\hline Baseline SGRQ symptom & $68.5(19.0)$ & $66.0(17.9)$ \\
\hline Baseline SGRQ activity & $53.0(26.9)$ & $56.3(27.0)$ \\
\hline Baseline SGRQ impact & $40.8(20.4)$ & $41.4(18.3)$ \\
\hline \multicolumn{3}{|c|}{$\begin{array}{l}\text { Data are mean }(\mathrm{SD}) \text { unless otherwise stated. } \\
\text { *Percentage expressed as a proportion of samples obtained. } \\
\text { AECOPD, acute exacerbation of chronic obstructive pulmonary disease; } \mathrm{BCSS} \text {, } \\
\text { Breathlessness, Cough and Sputum } \mathrm{Scale} \text {; } \mathrm{FV}_{1} \text {, forced expiratory volume in the first } \\
\text { second; } \mathrm{PEP} \text {, positive expiratory pressure; } \mathrm{P}_{\mathrm{a}} \mathrm{O}_{2} \text {, partial pressure of oxygen (arterial); } \\
\mathrm{P}_{\mathrm{a}} \mathrm{CO}_{2} \text {, partial pressure of carbon dioxide (arterial); } \mathrm{pH} \text {, power of hydrogen; SGRQ, St } \\
\text { George's Respiratory Questionnaire. }\end{array}$} \\
\hline
\end{tabular}

to complete their physical exercise regime as required. The incidence of serious clinical deterioration due to all causes or acute sputum retention in both groups was low and did not significantly differ (table 2 ).

\section{Primary outcome}

Mean BCSS scores improved steadily in both groups from admission to 6 months, however, the between-group differences were not significant (interaction effect, $\mathrm{p}=0.978$ ) (figure 2, table 3). No significant differences were apparent for any mean breathlessness, cough or sputum component scores (non-total) over time. Daily BCSS scores varied considerably from day to day during the follow-up period (frequently $>1$ point), yet were not regularly associated with HCU or onset of antibiotics or corticosteroids.

\section{Secondary outcomes}

There were no significant differences in mean SGRQ total or component (symptoms, activity, impact) scores between the two groups over time (table 3), however, both groups demonstrated improvements from admission to 8 weeks in excess of the minimum clinically important difference (MCID) of four points. ${ }^{16}$

No significant differences were found between groups for mean hospital length of stay or use of ventilatory assistance (table 2). The median incidence of exacerbations, hospitalisations and antibiotic therapy in both groups during the follow-up period was low and not significantly different (table 4). There were no significant between-group differences in the time to first exacerbation $(p=0.599$, figure 3 ) or first hospitalisation $(p=0.257$, figure 4). Participation in pulmonary rehabilitation during the follow-up period did not differ between groups.

Total BODE scores did not differ significantly between groups over time, however, a significant difference was detected for mMRC scores $(p=0.006$, figure 5$)$. For participants in the PEP group only, mean mMRC scores improved from discharge to 8 weeks, but this was not maintained at 6 months. Exercise tolerance $(6 \mathrm{MWD})$ tended to improve more rapidly in the PEP group $(\mathrm{p}=0.052$, figure 6$)$.

Table 2 Summary of inpatient management

\begin{tabular}{|c|c|c|c|}
\hline & Control $(n=45)$ & $\operatorname{PEP}(n=45)$ & $\begin{array}{l}\mathrm{p} \\
\text { Value }\end{array}$ \\
\hline Bronchodilator therapy & $44(98)$ & $45(100)$ & 0.315 \\
\hline Antibiotic therapy & $44(98)$ & $45(100)$ & 0.315 \\
\hline Steroids (intravenous, oral) & $40(89)$ & $43(96)$ & 0.238 \\
\hline Oxygen therapy & $30(67)$ & $35(78)$ & 0.239 \\
\hline Need for ventilatory assistance & $6(13)$ & $11(24)$ & 0.178 \\
\hline Ventilatory assistance $<48 \mathrm{~h}$ & $4(9)$ & $10(22)$ & 0.081 \\
\hline Ventilatory assistance $>48 \mathrm{~h}$ & $4(9)$ & $4(9)$ & 1.000 \\
\hline $\begin{array}{l}\text { Ventilatory assistance } \\
\text { duration, hours }\end{array}$ & $18(2.3-192.9)$ & $10.9(1.8-50.1)$ & 0.743 \\
\hline Time until weaned, days & $1.41(0.1-20.2)$ & $0.63(0.1-6.4)$ & 0.743 \\
\hline $\begin{array}{l}\text { Serious clinical deterioration } \\
\text { (all-cause) }\end{array}$ & $6(13)$ & $9(20)$ & 0.396 \\
\hline $\begin{array}{l}\text { Development of acute sputum } \\
\text { retention }\end{array}$ & $5(11)$ & $3(7)$ & 0.459 \\
\hline Hospital length of stay, days & $4.3(2.9-7.6)$ & $4.9(3.0-7.3)$ & 0.591 \\
\hline
\end{tabular}




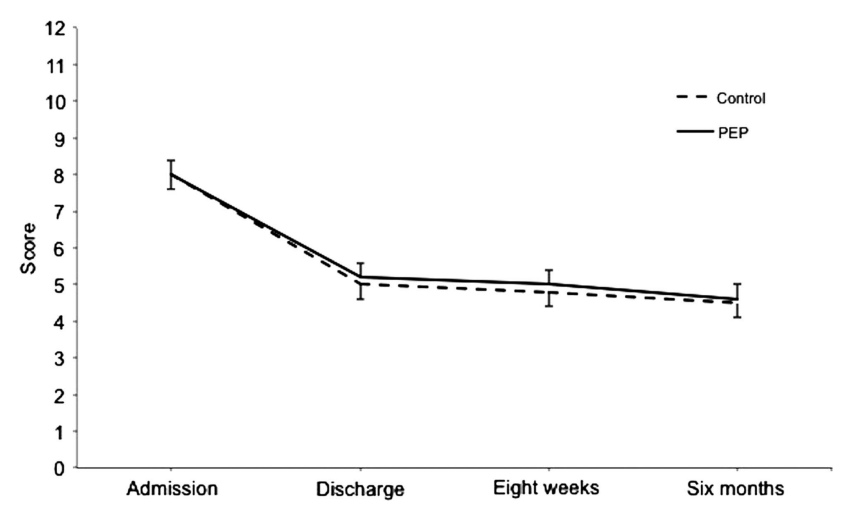

Figure 2 Mean (SE) Breathlessness, Cough and Sputum Scale scores over time. PEP, positive expiratory pressure; $p=0.978$ (linear mixed model interaction effect).

Two participants (one from each group) died during the initial hospital admission. Ten (4 PEP) were deceased at study completion ( $p=0.484$ for between-group comparison, table 4 ).

\section{Subgroup analyses}

The nature (infective or non-infective) of the initial AECOPD $(p=0.180)$ and the need for ventilatory assistance $(p=0.342)$ did not significantly influence the severity of symptoms over time. There was no significant effect due to exacerbations after discharge $(p=0.050)$, however, mean BCSS scores for participants in the control group who did not experience an exacerbation were consistently lower (better) than others.

\section{Baseline variables associated with symptom severity at discharge}

The need for ventilatory assistance within the first $48 \mathrm{~h}$ of admission was significantly associated with a 2.4 unit (SE 0.97) reduction (improvement) in BCSS scores at discharge. A history of low usual sputum production ( $<1$ teaspoon/day) was significantly associated with a 1.3 unit (SE 0.57) increase (worsening) in BCSS scores at discharge. The regression model was significant $(p=0.011)$ but explained only $17 \%$ of the total variance in the mean discharge BCSS score (based on the adjusted R Square statistic).

\section{DISCUSSION}

This was one of the largest studies to evaluate the effectiveness of an ACT during a hospitalised AECOPD. The results are clinically relevant as the pragmatic study design involved treatment by usual physiotherapy and medical staff in a typical hospital environment. Compared to usual care and physical exercise, additive PEP therapy demonstrated minimal benefit on shortterm and long-term outcomes relevant to patients and healthcare providers.

The symptom severity (BCSS) scores reported during the initial hospital admission (mean admission score 7.5) were greater than those previously reported. ${ }^{15} 22$ Large improvements until discharge occurred in both groups (mean discharge score 5.1), however, the mean between-group differences were neither statistically nor clinically significant (table 3). This was most likely explained by a negligible treatment effect, not by instrument insensitivity. This lack of treatment effect in BCSS scores was reported in a recent large RCT $(n=527)$ comparing manual chest physiotherapy techniques (percussions and vibrations) with breathing exercises to breathing exercises alone during an AECOPD. ${ }^{22}$

Participants in the PEP group demonstrated more rapid improvements in dyspnoea (mMRC scores) after discharge compared to those in the control group. The magnitude of score differences within or between groups over any timepoints, however, was less than the MCID of one point. ${ }^{23}$ Conversely, the trend regarding between-group differences for 6MWD failed to reach statistical significance, yet the mean change from discharge to 8 weeks for the PEP group $(53 \mathrm{~m})$ exceeded the MCID of $25 \mathrm{~m}^{24} 25$ These small, delayed effects of PEP therapy seem unusual for a cohort of patients who do not usually perform ACTs at home and appear to lack clinical significance.

There are very few studies of PEP therapy during AECOPDs to enable comparison of our results. A study $(n=27)$ by Bellone and colleagues ${ }^{9}$ found PEP mask therapy safe and effective for patients

Table 3 Between-group comparisons of adjusted mean (SE) data from linear mixed-model analyses

\begin{tabular}{|c|c|c|c|c|c|c|c|c|c|c|}
\hline \multirow[b]{2}{*}{ Outcome } & \multicolumn{3}{|c|}{ Discharge } & \multicolumn{3}{|c|}{ 8-week follow-up } & \multicolumn{3}{|c|}{ 6-month follow-up } & \multirow[b]{2}{*}{ p Value } \\
\hline & $\mathbf{n}$ & Control & PEP & $\mathbf{n}$ & Control & PEP & $\mathbf{n}$ & Control & PEP & \\
\hline BCSS & 80 & $5.0(0.4)$ & $5.2(0.4)$ & 78 & $4.8(0.4)$ & $5.0(0.4)$ & 71 & $4.5(0.4)$ & $4.6(0.4)$ & 0.978 \\
\hline Group difference, mean $(95 \% \mathrm{Cl})$ & \multicolumn{3}{|c|}{$0.2(-0.9$ to 1.4$)$} & \multicolumn{3}{|c|}{$0.2(-0.9$ to 1.4$)$} & \multicolumn{3}{|c|}{$0.1(-1.1$ to 1.3$)$} & \\
\hline SGRQ-Total & . & . & . & 72 & $40.8(2.8)$ & $41.6(2.6)$ & 71 & $40.6(2.8)$ & $42.1(2.6)$ & 0.872 \\
\hline Group difference, mean $(95 \% \mathrm{Cl})$ & & & & \multicolumn{3}{|c|}{$0.8(-6.7$ to 8.3$)$} & \multicolumn{3}{|c|}{$1.4(-6.1$ to 9.0$)$} & \\
\hline SGRQ_-symptoms & . & . & . & 72 & $52.8(3.6)$ & $55.8(3.4)$ & 72 & $56.0(3.5)$ & $58.4(3.4)$ & 0.909 \\
\hline SGRQ_-activity & . & . & . & 72 & $48.9(3.8)$ & $46.9(3.6)$ & 71 & $46.7(3.8)$ & $45.5(3.6)$ & 0.899 \\
\hline SGRQ_-impact & . & . & . & 72 & $32.9(2.8)$ & $34.2(2.6)$ & 71 & $32.4(2.8)$ & $34.9(2.6)$ & 0.783 \\
\hline BODE & 65 & $5.3(0.5)$ & $5.8(0.4)$ & 38 & $5.1(0.5)$ & $5.2(0.5)$ & 26 & $5.0(0.6)$ & $5.6(0.6)$ & 0.608 \\
\hline Group difference, mean $(95 \% \mathrm{Cl})$ & \multicolumn{3}{|c|}{$0.5(-0.7$ to 1.8$)$} & \multicolumn{3}{|c|}{$0.1(-1.3$ to 1.5$)$} & \multicolumn{3}{|c|}{$0.6(-1.1$ to 2.2$)$} & \\
\hline $\mathrm{BMI}, \mathrm{kg} / \mathrm{m}^{2}$ & 76 & $26.5(1.1)$ & $24.1(1.1)$ & 53 & $26.2(1.2)$ & $23.8(1.1)$ & 38 & $23.6(1.4)$ & $22.3(1.2)$ & 0.711 \\
\hline $\mathrm{FEV}_{1}, \%$ predicted & 71 & $35.9(1.4)$ & $35.6(1.4)$ & 47 & $36.6(1.9)$ & $36.5(1.6)$ & 32 & $37.7(2.4)$ & $36.4(1.9)$ & 0.941 \\
\hline $\mathrm{mMRC}$ & 84 & $2.4(0.2)$ & $2.8(0.2)$ & 72 & $2.6(0.2)$ & $2.2(0.2)$ & 71 & $2.4(0.2)$ & $2.9(0.2)$ & 0.006 \\
\hline 6MWD, m & 68 & $297(23.2)$ & $271(22.7)$ & 44 & $296(25.1)$ & $324(24.2)$ & 29 & $337(29.3)$ & $333(27.3)$ & 0.052 \\
\hline
\end{tabular}


Table 4 Summary of outcome data measured at 6 months

\begin{tabular}{|c|c|c|c|c|}
\hline & n Control & n & PEP & p Value \\
\hline Number of AECOPDs & $431(0.0-3.0)$ & 45 & $1(0.5-3.0)$ & 0.986 \\
\hline $\begin{array}{l}\text { Number of respiratory-related } \\
\text { hospitalisations }\end{array}$ & $420(0.0-1.0)$ & 44 & $1(0.0-1.75)$ & 0.359 \\
\hline Total number of hospitalised days & $420(0.0-10.1)$ & 43 & $1.8(0.0-9.3)$ & 0.397 \\
\hline Need for antibiotics & $431(0.0-3.0)$ & 45 & $2(0.0-3.0)$ & 0.384 \\
\hline Mortality, n (\%) & $446(14)$ & 45 & $4(9)$ & 0.484 \\
\hline
\end{tabular}

with acute hypercapnoeic respiratory failure requiring NIV compared with usual care, however effectiveness was defined by enhanced sputum expectoration and improved weaning time. In the present study, the incidence of NIV was much lower and no benefits regarding weaning were observed. Sputum expectoration was not measured during the current study, however, the limitations of this outcome are well documented. ${ }^{26}$

Due to a slower than anticipated recruitment rate it was not possible to reach the target of 98 participants. However, it appears unlikely that an additional eight participants would have affected the findings relating to the primary outcome. The large day-to-day variability in total BCSS scores observed throughout this study suggests the variability in our sample was greater than that from which the power calculations were derived. ${ }^{15}$ This highlights a challenge in identifying sensitive outcomes for airway clearance studies. Other limitations include the lack of sham ACT in the control group and concomitant failure to control for physiotherapist time. The study was not powered to detect a difference for some secondary outcomes (QOL, exacerbations and hospitalisations), however, the results were consistent with previous studies of ACTs in AECOPDs. ${ }^{22} 27$ The low incidence of adverse events and overall mortality was also consistent with those previously reported. ${ }^{8} 28$

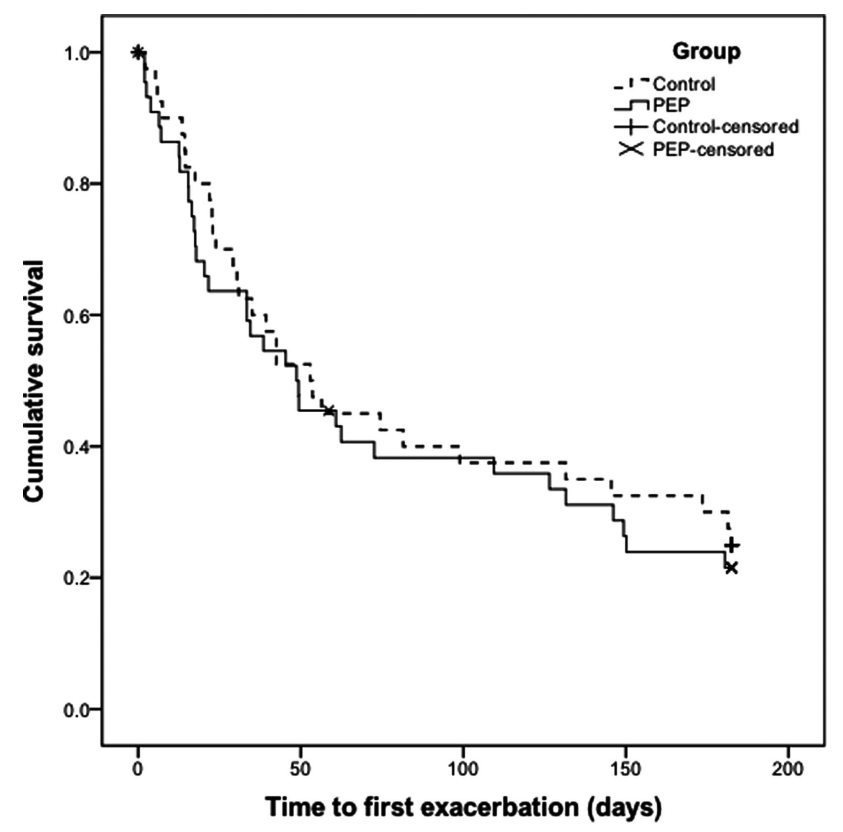

Figure 3 Time to first exacerbation. PEP, positive expiratory pressure; $\mathrm{p}=0.599$.

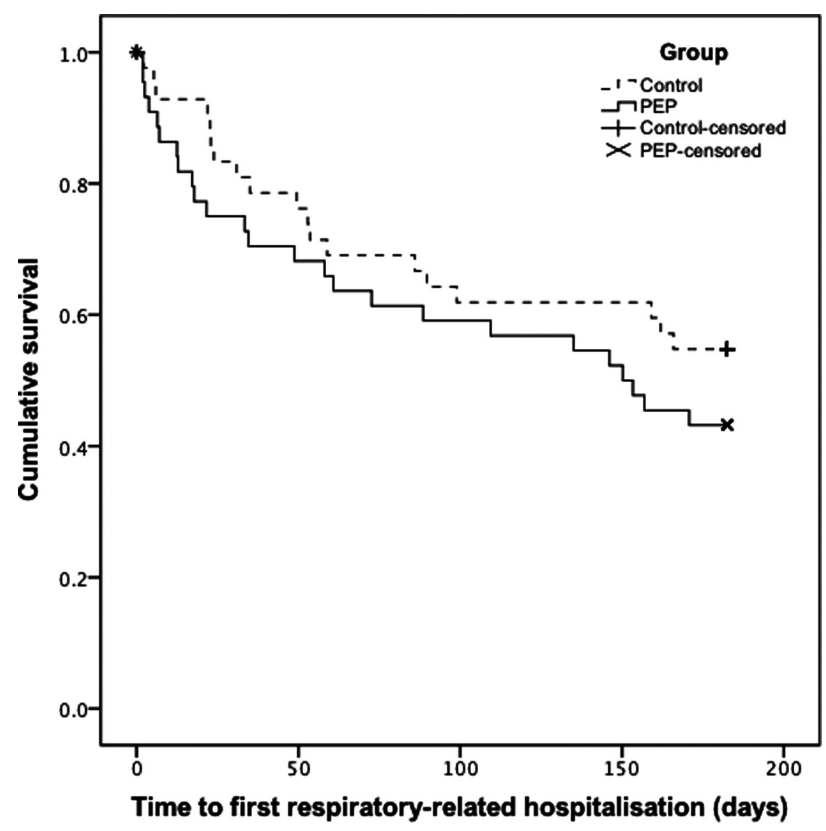

Figure 4 Time to first respiratory-related hospitalisation. PEP, positive expiratory pressure; $\mathrm{p}=0.257$.

This study reiterated the safety and tolerability of PEP therapy in patients with an AECOPD. Logistic issues concerning its use in patients with concurrent oxygen therapy or NIV were overcome via simple mouthpiece adaptations, however, the potential effect of nasal air-leak due to the absence of a noseclip was not monitored. While PEP therapy remains relatively infrequently prescribed for patients with an AECOPD compared to other breathing exercises, ${ }^{7}$ 29-31 this is more likely due to limiting factors such as access and cost of commercially available equipment.

It has been proposed that patients with copious secretions $(30 \mathrm{~mL} /$ day) or an impaired cough may benefit more from ACTs than others. ${ }^{32}{ }^{33}$ While this study did not seek answers to these specific questions, we identified that consideration of patients' need for early ventilatory assistance and usual sputum expectoration may be important determinants of symptom severity at hospital discharge. Identifying a COPD 'ACT responder' group remains a potentially valuable clinical prospect, however, this may prove unfeasible due to the significant sample sizes required

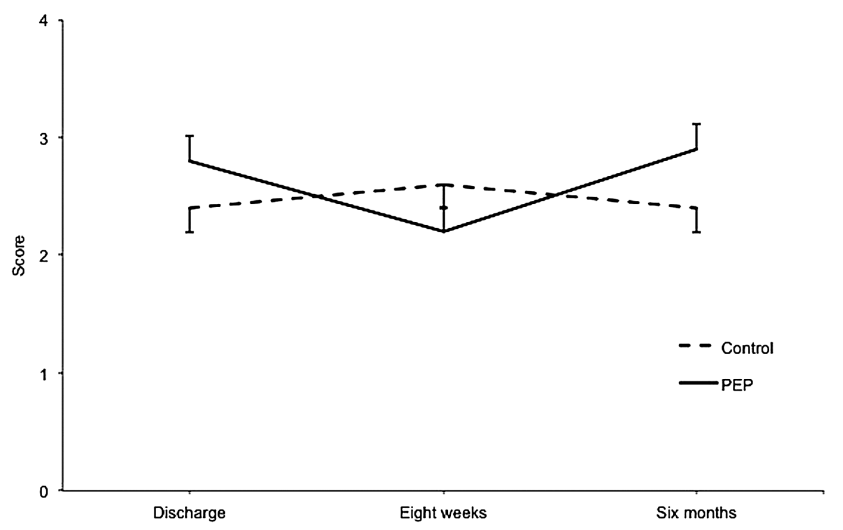

Figure 5 Mean (SE) modified Medical Research Council dyspnoea scale scores over time. PEP, positive expiratory pressure; $p=0.006$ (linear mixed model interaction effect). 


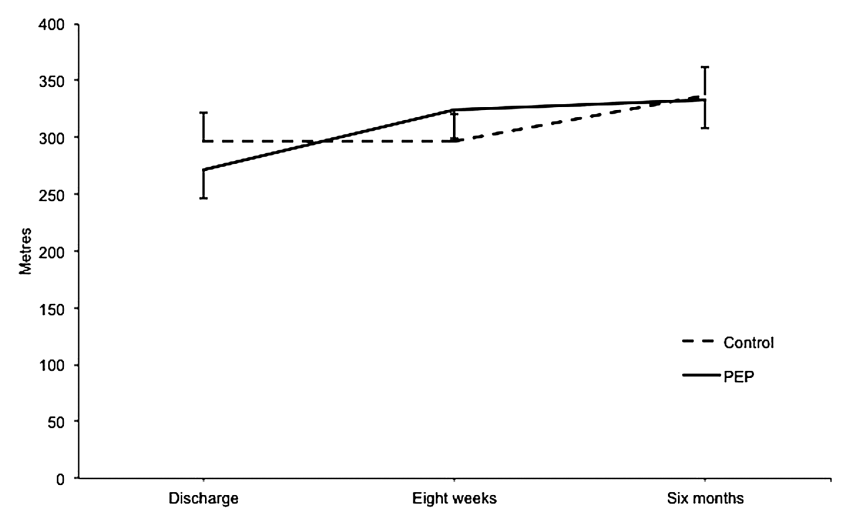

Figure 6 Mean (SE) 6 min walk distance over time. PEP, positive expiratory pressure; $p=0.052$ (linear mixed model interaction effect).

for statistical power when using outcomes of high clinical importance.

In conclusion, this study did not show any appreciable benefit of PEP therapy on symptoms, QOL or incidence of future exacerbations in patients with an AECOPD and associated sputum production, despite large study numbers and strong methodological rigour. Careful consideration of the aims and effectiveness of such therapy should therefore be made before advocating for PEP therapy in patients with AECOPD. Our findings do not support a routine role for PEP therapy in AECOPD, even in those productive of purulent sputum.

Correction notice This article has been corrected since it was published Online First. The corresponding author's email address has been updated.

Acknowledgements The authors would like to thank the physiotherapy staff at The Alfred Hospital and Austin Health including Dr. Brenda Button and Ms. Sarah Foss for their assistance, and Mr. Steve Vander Hoorn for statistical advice. We also thank the participants of this study for their time and cooperation.

Contributors CRO (principal contributor guarantor)—overall study coordinator, study conception, blinded outcome assessor, data analysis, results interpretation, manuscript write-up and review. CFMcD—study conception, project supervision, patient treatment, results interpretation, manuscript review. BRM—project supervision, patient treatment, manuscript review. $\mathrm{CJH}$ - study conception, patient treatment, results interpretation, manuscript review. BT—study conception, patient treatment, results interpretation, manuscript review. RS—study conception, patient treatment, results interpretation, manuscript review. CC-study conception, patient treatment, results interpretation, manuscript review. NS—study conception, patient treatment, results interpretation, manuscript review. $\mathrm{CCO}-$ blinded outcome assessor, project coordination, results interpretation, manuscript review. NG - blinded outcome assessor, project coordination, results interpretation, manuscript review. AEH—overall study supervisor, study conception, data analysis, results interpretation, manuscript write-up and review.

Funding CO received a La Trobe University Postgraduate Scholarship and grants from the Australian Physiotherapy Association Physiotherapy Research Foundation (S10-010), the Institute for Breathing and Sleep, and La Trobe University.

Competing interests None.

Ethics approval La Trobe University, Alfred Health and Austin Health.

Provenance and peer review Not commissioned; externally peer reviewed.

\section{REFERENCES}

1 Donaldson GC, Seemungal TA, Bhowmik A, et al. Relationship between exacerbation frequency and lung function decline in chronic obstructive pulmonary disease. Thorax 2002; 57:847-52.

2 Kanner RE, Anthonisen NR, Connett JE. Lower respiratory illnesses promote FEV(1) decline in current smokers but not ex-smokers with mild chronic obstructive pulmonary disease: results from the lung health study. Am J Respir Crit Care Med 2001;164:358-64.

3 Seemungal TA, Donaldson GC, Paul EA, et al. Effect of exacerbation on quality of life in patients with chronic obstructive pulmonary disease. Am J Respir Crit Care Med 1998;157(5 Pt 1):1418-22.

4 Calverley PM, Anderson JA, Celli B, et al. Salmeterol and fluticasone propionate and survival in chronic obstructive pulmonary disease. N Eng/ J Med 2007;356:775-89.
5 Hurst JR, Donaldson GC, Quint JK, et al. Temporal clustering of exacerbations in chronic obstructive pulmonary disease. Am J Respir Crit Care Med 2009;179:369-74.

6 Osadnik C, Stuart-Andrews C, Ellis S, et al. Positive expiratory pressure via mask does not improve ventilation inhomogeneity more than huffing and coughing in individuals with stable chronic obstructive pulmonary disease and chronic sputum expectoration. Respiration. Published Online First: 8 June 2013. doi: 10.1159/ 000348546

7 Osadnik CR, McDonald CF, Holland AE. Airway clearance techniques in acute exacerbations of COPD: a survey of Australian physiotherapy practice. Physiotherapy 2013:99:101-6

8 Osadnik CR, McDonald CF, Jones AP, et al. Airway clearance techniques for chronic obstructive pulmonary disease. Cochrane Database Syst Rev 2012;(3):CD008328.

9 Bellone A, Spagnolatti L, Massobrio M, et al. Short-term effects of expiration under positive pressure in patients with acute exacerbation of chronic obstructive pulmonary disease and mild acidosis requiring non-invasive positive pressure ventilation. Intensive Care Medicine 2002;28:581-5.

10 Vargas F, Bui HN, Boyer A, et al. Intrapulmonary percussive ventilation in acute exacerbations of COPD patients with mild respiratory acidosis: a randomized controlled trial [with consumer summary]. Crit Care 2005;9:R382-9.

11 National Institute for Health and Clinical Excellence (NICE). Chronic Obstructive Pulmonary Disease: Management of Chronic Obstructive Pulmonary Disease in Adults in Primary and Secondary Care 2010 Jun. http://www.nice.org.uk/CG101 (accessed 15 Nov 2012).

12 Miravitlles M, Anzueto A, Legnani $D$, et al. Patient's perception of exacerbations of COPD—-the PERCEIVE study. Respir Med 2007;101:453-60.

13 McKenzie DK, Abramson M, Crockett AJ, et al. The COPD-X Plan: Australian and New Zealand Guidelines for the management of Chronic Obstructive Pulmonary Disease V2.30, 2011 2011. http://www.copdx.org.au/ (accessed 15 Nov 2012).

14 Holland $A E$, Button BM. Is there a role for airway clearance techniques in chronic obstructive pulmonary disease? Chron Respir Dis 2006;3:83-91.

15 Leidy NK, Rennard SI, Schmier J, et al. The breathlessness, cough, and sputum scale: the development of empirically based guidelines for interpretation. Chest 2003;124:2182-91.

16 Jones PW, Quirk FH, Baveystock CM. The St George's Respiratory Questionnaire. Respir Med 1991;85(Suppl B):25-31; discussion 3-7.

17 Fletcher CM, Elmes PC, Fairbairn AS, et al. The significance of respiratory symptoms and the diagnosis of chronic bronchitis in a working population. BMJ 1959;2:257-66.

18 Celli BR, Cote CG, Marin JM, et al. The body-mass index, airflow obstruction, dyspnea, and exercise capacity index in chronic obstructive pulmonary disease. $N$ Engl J Med 2004;350:1005-12.

19 Cote CG, Dordelly LJ, Celli BR. Impact of COPD exacerbations on patient-centered outcomes. Chest 2007;131:696-704.

20 Fitzmaurice GM, Laird NM, Ware JH. Applied longitudinal analysis. 2nd edn. New Jersey, USA: John Wiley \& Sons, Inc., 2011.

21 Anthonisen NR, Manfreda J, Warren CP, et al. Antibiotic therapy in exacerbations of chronic obstructive pulmonary disease. Ann Intern Med 1987;106:196-204.

22 Cross J, Elender F, Barton G, et al. A randomised controlled equivalence trial to determine the effectiveness and cost-utility of manual chest physiotherapy techniques in the management of exacerbations of chronic obstructive pulmonary disease (MATREX). Health Technol Assess 2010;14:1-147, iii-iv.

23 de Torres JP, Pinto-Plata V, Ingenito E, et al. Power of outcome measurements to detect clinically significant changes in pulmonary rehabilitation of patients with COPD. Chest 2002;121:1092-8.

24 Puhan MA, Mador MJ, Held U, et al. Interpretation of treatment changes in 6-minute walk distance in patients with COPD. Eur Respir J 2008;32:637-43.

25 Holland AE, Hill CJ, Rasekaba T, et al. Updating the minimal important difference for six-minute walk distance in patients with chronic obstructive pulmonary disease. Arch Phys Med Rehabil 2010;91:221-5.

26 van der Schans CP, Postma DS, Koeter GH, et al. Physiotherapy and bronchial mucus transport. Eur Respir J 1999;13:1477-86.

27 Kodric M, Garuti G, Colomban M, et al. The effectiveness of a bronchial drainage technique (ELTGOL) in COPD exacerbations. Respirology 2009;14:424-8.

28 Geelhoed EA, Brameld KJ, Holman CD, et al. Readmission and survival following hospitalization for chronic obstructive pulmonary disease: long-term trends. Intern Med J 2007;37:87-94.

29 Harth L, Stuart J, Montgomery C, et al. Physical therapy practice patterns in acute exacerbations of chronic obstructive pulmonary disease. Can Respir J 2009;16:86-92.

30 Lee A, Button B, Denehy L. Current Australian and New Zealand physiotherapy practice in the management of patients with bronchiectasis and chronic obstructive pulmonary disease. N Z J Physiother 2008;36:49-58.

31 Yohannes AM, Connolly MJ. A national survey: percussion, vibration, shaking and active cycle breathing techniques used in patients with acute exacerbations of chronic obstructive pulmonary disease. Physiotherapy 2007:93:110-13.

32 Cochrane GM, Webber BA, Clarke SW. Effects of sputum on pulmonary function. BMJ 1977;2:1181-3.

33 Graham WG, Bradley DA. Efficacy of chest physiotherapy and intermittent positive-pressure breathing in the resolution of pneumonia. $N$ Engl I Med 1978;299:624-7. 